\title{
Evaluation of Antidiabetic Potential of Pinus roxburghii Bark Extract in Alloxan Induced Diabetic Rats
}

\section{Kaushik P, Khokra SL and Kaushik D*}

Institute of Pharmaceutical Sciences, Kurukshetra University, Kurukshetra-136119, Haryana, India

\begin{abstract}
In the present study we investigated the possible anti-diabetic potential of Pinus roxburghii Sarg. in alloxan induced diabetic rat. Diabetes was induced in rats by injecting them with alloxan (120 mg/kg body weight). Control rats were either healthy untreated, or diabetes induced untreated rats which only received distilled water. The acute effect of ethanol extract was evaluated by administering $100,300,500 \mathrm{mg} / \mathrm{kg}$ body weight p.o. to normoglycemic rats. In the chronic model, the ethanol extract was administered to normal and alloxan-induced-diabetic rats at dose of $100,300,500 \mathrm{mg} / \mathrm{kg}$ body weight p.o. per day for 21 days. Blood glucose levels and body weights were monitored at specific intervals and different biochemical parameters were also carried out. The statistical data indicated the significant $(p<0.01)$ increase in the body weight and decrease in the blood glucose, glycated hemoglobin levels, total cholesterol and serum triglycerides. HDL cholesterol level was significantly $(p<0.01)$ increased when treated with the extract. Quercetin isolated from the bark of plant showed $a$-amylase inhibitory activity .Hence, it can be concluded that antihyperglycemic and antihyperlipidemic activities of ethanol extract of Pinus roxburghii Sarg. Bark may be due to the presence of phytoconstituents like flavanoids.
\end{abstract}

Keywords: Pinus roxburghii Sarg; Antihyperglycemic; Antihyperlipidemic; Alloxan; Diabetes; Quercetin

\section{Introduction}

Diabetes mellitus is one of the most common chronic diseases across the world and number of diabetic patients is on rise. The World Health Organization (WHO) estimates that nearly 200 million people all over the world suffering from diabetes and this number are likely to be doubled by 2030 [1]. The recently published Indian council for medical research-India diabetes national study reported that there are 62.4 million people with type 2 diabetes (T2DM) and 77 million people with pre-diabetes in India [2]. This will be increased to 100 million by 2030 [3]. T2DM predominantly affects older individuals in developed countries, while in developing nations like India; it is affecting the younger population in the prime of their working lives and thus poses an even greater threat to the health of these individuals [2,4]. Many Indian medicinal plants are being examined for their beneficial use in diabetes. Bark and roots of many plants alongwith Pinus roxburgii Sarg. have been used to treat diabetes ethnopharmacologically [5]. Pinus roxburghii Sarg. named after William Roxburgh, is a pine inhabitant to the Himalaya, the range extends from northern Pakistan (North-West Frontier Province, Azad Kashmir), across northern India (Jammu and Kashmir, Punjab, Himachal Pradesh, Uttrakhand, Sikkim) and Nepal to Bhutan [6]. Pinus roxburghii Sarg. has been attributed to many pharmacological activities like hepatoprotective [7], anti-inflammatory, analgesic [8] anticonvulsant [9] antimicrobial [10], antibacterial [11] and anticancer activities [12]. Bark of Pinus roxburghii Sarg. has been used to treat diabetes ethnopharmacologically in India and Africa [13]. Pinus roxburghii Sarg. is known to be a rich source of terpenoids, flavanoids, thereforeit is of great interest to study its therapeutic effect. Almost all the parts of the plant (bark, leaves and root) are found to contain active principles [14-17]. Our recent in silico studies showed that secoisoresinol from bark of Pinus roxburghii Sarg. is effective against aldose reductase enzyme [18], which is mainly responsible for daibetic secondary complications [19]. Moreover our current in vitro research on bioactivity guided isolation for $\alpha$-amylase inhibitor, an active constituent namely quercetin isolated for the first time from the bark of plant showed $\alpha$-amylase inhibitory activity [20].
In the present study, we investigate the possible antidiabetic potential of ethanol extract of Pinus roxburghii Sarg. bark (PRB) in alloxaninduced diabetic rat.

\section{Materials and Methods}

Collection of plant material-The bark of Pinus roxburghii Sarg. were collected from the hilly region of Morni, District Panchkula, Haryana, in the month of February 2013 and was authenticated by FRI, Dehradun, Uttarakhand, India, where a voucher specimen no. 129 FHH was deposited for future reference.

Preparation of extract-Shade dried coarse powdered bark of Pinus roxburghii Sarg. in a quantity sufficient as per the volume of the extractor was packed in a thimble (made of filter paper sheet). A sufficient volume of ethanol was added to the reservoir, and hot continuous extraction process in a Soxhlet extractor was started. This extraction process was continued for about 48 hours or until ethanol coming down the siphoning tube became colorless. The overabundance of ethanol was distilled under reduced pressure using a rotatory vacuum evaporator. (Heidolph Laborota 4011, digital). A brown residue was recovered from flask with $18 \%$ yield. Stored at $2-4^{\circ} \mathrm{C}$ for further analysis.

Animals-Male Sprague-Dawley rats (200-250 gm) were used. They were kept at $25 \pm 2^{\circ} \mathrm{C}$ in a $12 \mathrm{~h}$ light, dark cycle with lights on at $07: 00 \mathrm{~h}$ and fed the standard pellet rat diet [Ashirwad Industries, Tirpari, Ropar (Punjab)] and water ad libitum. Institutional Animal

*Corresponding author: Dhirender Kaushik, Institute of Pharmaceutical Sciences, Kurukshetra University, Kurukshetra-136119, Haryana, India, Tel: +919416055522; Email: dkaushik.apti@gmail.com

Received September 11, 2015; Accepted October 06, 2015; Published October 10,2015

Citation: Kaushik P, Khokra SL and Kaushik D (2015) Evaluation of Antidiabetic Potential of Pinus roxburghii Bark Extract in Alloxan Induced Diabetic Rats. J Pharmacogn Nat Prod 1: 105. doi:10.4172/2472-0992.1000105

Copyright: $\odot 2015$ Kaushik $P$ et al. This is an open-access article distributed unde the terms of the Creative Commons Attribution License, which permits unrestricted use, distribution, and reproduction in any medium, provided the original author and source are credited. 
Ethics Committee, constituted under the guidelines of CPCSEA, Ministry of Environment, Govt. of India, New Delhi, Approved all the animal experimental protocols (Registration Number: 562/GO/ 02/a/ CPCSEA).

Acute toxicity study-Toxicity studies conducted as per internationally accepted protocol drawn under OECD guidelines 425 in Sprague-Dawley rats [21].

Oral glucose tolerance test(OGTT)-Glucose tolerance tests were performed in treated and control rats, according to the method described by Kaushik et al. [22] with some modifications. Distilled water, PRB $(100 \mathrm{mg} / \mathrm{kg}, 300 \mathrm{mg} / \mathrm{kg}, 500 \mathrm{mg} / \mathrm{kg}$ body weight) or glibenclamide $(2.5 \mathrm{mg} / \mathrm{kg}$ body weight $)$ was administered orally to five different groups of overnight fasting rats. Glucose ( $4 \mathrm{~g} / \mathrm{kg}$ body weight) was fed orally $30 \mathrm{~min}$ after treatment. Blood was withdrawn from retro orbital sinus at $0,30,60,90$ and $120 \mathrm{~min}$ from control and treated animals. The plasma obtained after centrifugation was used for the determination of plasma glucose levels by a glucose-oxidase method.

Induction of experimental diabetes-Diabetes mellitus was induced in $12 \mathrm{~h}$ fasted animals by intraperitoneal injection of alloxan monohydrate (Sigma, St. Louis, Mo., USA) dissolved in sterile normal saline at a dosage of $120 \mathrm{mg} / \mathrm{kg}$ body weight [23]. Since alloxan is capable of producing fatal hypoglycemia as a result of the massive pancreatic insulin release, rats were treated with $20 \%$ glucose solution intraperitoneally $6 \mathrm{~h}$ after alloxan treatment. Diabetes was confirmed in alloxan-treated rats by measuring fasting blood glucose levels 72 $\mathrm{h}$ after alloxan treatment. Rats with marked hyperglycemia (blood glucose level above $150 \mathrm{mg} / \mathrm{dl}$ were selected and used in the study. This model has been applied in earlier studies to cause type II diabetes in rats [24-26]. Gliblenclamide $(2.5 \mathrm{mg} / \mathrm{kg})$ was used as standard drug.

Antidiabetic study-Animals were divided into six groups, each consisting of five rats. Group-I: Normal control+distilled water. GroupII: Diabetic control+distilled water. Group III: Diabetic+glibenclamide ( $2.5 \mathrm{mg} / \mathrm{kg}$ body weight). Group IV: Diabetic+PRB (100 mg/kg body weight); Group V: Diabetic PRB (300 mg/kg body weight); Group VI: Diabetic+PRB ( $500 \mathrm{mg} / \mathrm{kg}$ body weight). The extract and standard drug solutions were suspended using tween 80 as a suspending agent for oral administration and administered for 21 days.

Biochemical analysis-Rats were fasted overnight and blood was withdrawn by retro-orbital sinus using ketamine on $1^{\text {st }}, 7^{\text {th }}, 14^{\text {th }}$ and $21^{\text {st }}$ day to determine blood glucose level. The changes in body weight were observed throughout the treatment period in experimental animals.

At the end of 21 days, animals were deprived of food overnight and sacrificed by cervical decapitation for biochemical parameters (i.e., glycated hemoglobin, serum createnin, serum urea, alkaline phosphatase, SGOT, SGPT and lipid profile) estimation. Serum lipid profiles and serum createnin, serum urea, alkaline phosphatase, SGOT, SGPT were measured by commercially available kits using an autoanalyzer (ERBA automated blood analyser). Glycated hemoglobin level as described by Nayak and Pattabiraman [27].

Stastical analysis-Data are expressed as mean \pm S.E.M. The data were analyzed by one-way analysis of variance (ANOVA) followed by Dunett's " $t$ " test to ascertain the level of significance using GraphPad InStat version 3.05 for Windows, (GraphPad Software, San Diego California USA). Values of $\mathrm{p}<0.05$ were considered statistically significant.

\section{Results}

Acute Toxicity Test of PRB-PRB was found safe up to the dose of $5000 \mathrm{mg} / \mathrm{kg}$ body weight according to OECD guidelines 425 .

Oral glucose tolerance test (OGTT) Figure 1 depicts the hypoglycemic effects of single oral administration of the extracts at 100 , 300 and $500 \mathrm{mg} / \mathrm{kg}$ body weight on OGTT of normal rats. PRB at the dose of $500 \mathrm{mg} / \mathrm{kg}$ body weight produced a maximum fall at $30 \mathrm{~min}$ after glucose administration.

Effect on body weight-Body weight decrease is common feature of diabetes due to the increased muscle wasting and loss of tissue proteins. Treatment with PRB, to diabetic rats (group IV to group VI) showed a significant $(p<0.01)$ dose dependant increase in body weight compared to the animals of diabetic control group as shown in Table 1 .

Effect on blood glucose levels-Table 2 describes the effect of treatment of the extract on fasting blood glucose levels. Significant $(p<0.01)$ reduction was observed in the PRB treated rats.

Effect on biochemical parameters-PRB showed a dose-related significant $(\mathrm{p}<0.01)$ decrease in triglycerides compared to pretreatment levels (Table 3). PRB at the doses of 300 and $500 \mathrm{mg} / \mathrm{kg}$ body weight was more effective than $100 \mathrm{mg} / \mathrm{kg}$ body weight in reducing the total cholesterol levels and increasing HDL level. Administration of PRB for 21 days significantly $(\mathrm{p}<0.01)$ reduced SGOT, SGPT, alkaline phosphatase in diabetic groups at dose dependant manner. On the other hand different doses of PRB significantly $(\mathrm{p}<0.01)$ reduced serum creatinine and serum urea level when compared to those of diabetic control groups.

Effect on glycated hemoglobin level-Significant $(\mathrm{p}<0.01)$ difference was observed in glycated hemoglobin levels when compared to diabetic control group (Table 4).

\section{Discussion}

The present manuscript discusses about the antihyperglycemic and antihyperlipidemic effects of the PRB on normal and alloxan-induced diabetic rats. Acute toxicity studies revealed the non-toxic nature of the PRB. There was no lethality or any toxic reactions found with the selected dose until the end of the study period. Alloxan causes a massive reduction in insulin release by the destruction of the $\beta$-cells of the islets of Langerhans, inducing hyperglycemia [28]. Impaired glucose tolerance is achieved due to deficiency of insulin in alloxan-induced diabetic rats by destructing the $\beta$-cells, which leads to type II diabetes [29]. Induction of diabetes by alloxan leads to loss of body weight due to the increased muscle wasting and loss of tissue proteins [30].

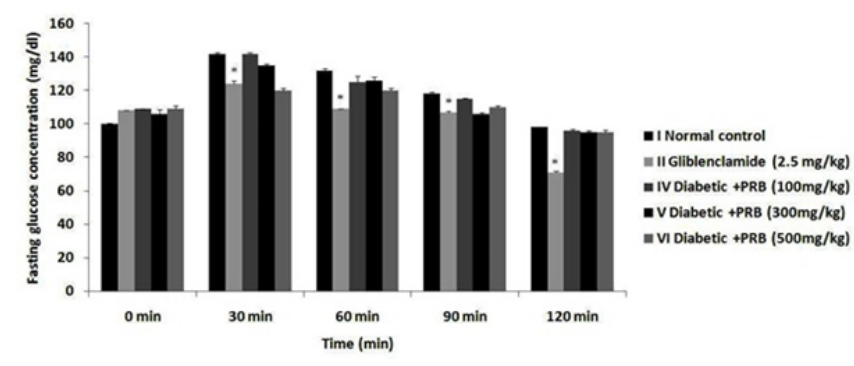

$\mathrm{p}<0.05$ significant from diabetic control animals

${ }^{*} p<0.01$ significant from diabetic control animals

Figure 1: Effect of PRB on serum glucose level during OGTT. Values are given as mean \pm SEM from five rats in each group. 
Citation: Kaushik P, Khokra SL and Kaushik D (2015) Evaluation of Antidiabetic Potential of Pinus roxburghii Bark Extract in Alloxan Induced Diabetic Rats. J Pharmacogn Nat Prod 1: 105. doi:10.4172/2472-0992.1000105

Page 3 of 5

\begin{tabular}{|c|c|c|c|c|c|}
\hline \multirow[t]{2}{*}{ Group } & \multirow[t]{2}{*}{ Treatment } & \multicolumn{4}{|c|}{ Body weight (gm) } \\
\hline & & $1^{\text {st }}$ day & $7^{\text {th }}$ day & $14^{\text {th }}$ day & $21^{\text {st }}$ day \\
\hline 1 & Normal control & $258 \pm 0.24$ & $260 \pm 0.25^{\star}$ & $256 \pm 0.58$ & $286 \pm 0.77^{* *}$ \\
\hline II & Diabetic control & $246 \pm 0.1$ & $188 \pm 0.83$ & $192 \pm 0.60$ & $174 \pm 0.09$ \\
\hline III & Diabetic+Gliblenclamide $(2.5 \mathrm{mg} / \mathrm{kg})$ & $228 \pm 0.94$ & $238 \pm 0.53$ & $240 \pm 0.11$ & $290 \pm 0.19^{* *}$ \\
\hline IV & Diabetic+PRB (100 mg/kg) & $256 \pm 0.41$ & $254 \pm 0.27$ & $256 \pm 0.91$ & $258 \pm 0.09^{* *}$ \\
\hline V & Diabetic+PRB (300 mg/kg) & $254 \pm 0.35$ & $240 \pm 0.03$ & $240 \pm 0.11$ & $256 \pm 0.06^{* *}$ \\
\hline VI & Diabetic+PRB (500 mg/kg) & $238 \pm 0.53$ & $286 \pm 0.93^{* *}$ & $244 \pm 0.66$ & $309 \pm 0.31^{* *}$ \\
\hline
\end{tabular}

Values are given as mean \pm S.E.M. from five rats in each group.

" $p<0.05$ significant from diabetic control animals

$\mathrm{p}<0.01$ significant from diabetic control animals

Table 1: Effect of PRB on body weight.

\begin{tabular}{|c|c|c|c|c|c|}
\hline \multirow[t]{2}{*}{ Group $(n=5)$} & \multirow[t]{2}{*}{ Treatment } & \multicolumn{4}{|c|}{ Fasting glucose concentration $(\mathrm{mg} / \mathrm{dl})$} \\
\hline & & $1^{\text {st }}$ day & $7^{\text {th }}$ day & $14^{\text {th }}$ day & $21^{\text {st }}$ day \\
\hline I & Normal control & $93.4 \pm 0.41^{* *}$ & $94.4 \pm 0.03^{* *}$ & $98.2 \pm 0.94^{* *}$ & $96.2 \pm 0.10^{* *}$ \\
\hline II & Diabetic control & $312 \pm 0.83$ & $290.60 \pm 0.58$ & $303 \pm 0.19$ & $298 \pm 0.4$ \\
\hline III & Diabetic+Gliblenclamide $(2.5$ mg/kg) & $312 \pm 0.74$ & $96.2 \pm 0.85^{\star *}$ & $95.6 \pm 0.80^{* *}$ & $91.6 \pm 0.23$ \\
\hline IV & Diabetic+PRB (100 mg/kg) & $312 \pm 0.60$ & $134 \pm 0.47^{\star *}$ & $143 \pm 0.51^{* *}$ & $141.4 \pm 0.19^{* *}$ \\
\hline V & Diabetic+PRB (300 mg/kg) & $298 \pm 0.60$ & $137 \pm 0.49^{* *}$ & $158 \pm 0.57^{* *}$ & $152.2 \pm 0.46^{* *}$ \\
\hline $\mathrm{VI}$ & Diabetic+PRB (500 mg/kg) & $318 \pm 0.83$ & $102.00 \pm 0.13^{* *}$ & $104 \pm 0.8^{* *}$ & $103 \pm 0.95^{* *}$ \\
\hline
\end{tabular}

Values are given as mean \pm SEM. from five rats in each group

${ }^{*} p<0.05$ significant from diabetic control animals

$p<0.01$ significant from diabetic control animals

Table 2: Effect of PRB on serum glucose level.

\begin{tabular}{|c|c|c|c|c|c|c|}
\hline Parameter/Groups & I & II & III & IV & $\mathbf{v}$ & VI \\
\hline $\mathrm{HDL}(\mathrm{mg} / \mathrm{dL})$ & $64.75 \pm 1.03^{* *}$ & $13.49 \pm 0.99$ & $38.52 \pm 0.09^{* *}$ & $42.13 \pm 0.32^{* *}$ & $51.96 \pm 1.5^{\star *}$ & $54.09 \pm 0.92^{* *}$ \\
\hline Triglycerides (mg/dL) & $12.68 \pm 0.48^{* *}$ & $54.52 \pm 0.55$ & $25.94 \pm 1.09^{* *}$ & $20.12 \pm 0.07^{* *}$ & $17.32 \pm 2.0^{* *}$ & $15.14 \pm 1.4^{* *}$ \\
\hline Total cholesterol (mg/dL) & $90.04 \pm 0.47^{* *}$ & $215.42 \pm 0.72$ & $130.22 \pm 0.75^{* *}$ & $129.86 \pm 0.75^{* *}$ & $126.84 \pm 0.47^{* *}$ & $116.92 \pm 0.07^{* *}$ \\
\hline Albumin (mg/dL) & $4.54 \pm 0.38^{* *}$ & $1.42 \pm 0.15$ & $2.51 \pm 0.49$ & $3.36 \pm 0.25^{* *}$ & $3.94 \pm 0.43^{* *}$ & $4.28 \pm 0.41^{* *}$ \\
\hline Serum Creatinine (mg/dL) & $0.08 \pm 0.04^{* *}$ & $4.2 \pm 0.23$ & $3.09 \pm 1.2$ & $2.8 \pm 0.02$ & $0.15 \pm 0.03^{* *}$ & $0.09 \pm 0.06^{* *}$ \\
\hline Serum urea $(\mathrm{mg} / \mathrm{dL})$ & $17.32 \pm 2.0^{* *}$ & $66.52 \pm 0.08$ & $45.94 \pm 1.0^{* *}$ & $49.92 \pm 0.23^{* *}$ & $25.14 \pm 1.4^{* *}$ & $20.68 \pm 0.7^{* *}$ \\
\hline SGPT (IU/L) & $11.52 \pm 0.30^{* *}$ & $44.90 \pm 0.44$ & $19.96 \pm 0.78^{* *}$ & $18.99 \pm 0.14$ & $17.94 \pm 1.8^{* *}$ & $14.07 \pm 0.38^{* *}$ \\
\hline SGOT (IU/L) & $14.93 \pm 2.8^{* *}$ & $114.96 \pm 0.43$ & $66.71 \pm 0.21^{* *}$ & $53.96 \pm 0.27^{* *}$ & $18.07 \pm 0.89^{* *}$ & $19.68 \pm 0.80^{* *}$ \\
\hline Alkaline phosphate (IU/L) & $120.25 \pm 0.9^{* *}$ & $228.34 \pm 0.30$ & $164.38 \pm 0.43^{* *}$ & $146.19 \pm 0.4^{* *}$ & $123.08 \pm 0.37^{* *}$ & $119.39 \pm 0.22^{* *}$ \\
\hline
\end{tabular}

Values are given as mean \pm SEM from five rats in each group

${ }^{*} \mathrm{p}<0.05$ significant from diabetic control animals

" $p<0.01$ significant from diabetic control animals

Table 3: Effect of PRB on different biochemical parameters.

\begin{tabular}{|c|c|c|}
\hline Group & Treatment & Glycated hemoglobin (\%) \\
\hline I & Normal control & $5.17 \pm 0.08^{* *}$ \\
\hline II & Diabetic control & $9.5 \pm 0.18$ \\
\hline III & Gliblenclamide $(2.5 \mathrm{mg} / \mathrm{kg})$ & $6.07 \pm 0.18^{* *}$ \\
\hline IV & Diabetic+PRB $(100 \mathrm{mg} / \mathrm{kg})$ & $8.3 \pm 0.24$ \\
\hline V & Diabetic+PRB $(300 \mathrm{mg} / \mathrm{kg})$ & $7.9 \pm 0.8^{*}$ \\
\hline VI & Diabetic+PRB $(500 \mathrm{mg} / \mathrm{kg})$ & $7.3 \pm 0.7^{*}$ \\
\hline
\end{tabular}

Values are given as mean \pm SEM from five rats in each group

${ }^{*} p<0.05$ significant from diabetic control animals

- $p<0.01$ significant from diabetic control animals

Table 4: Effect of PRB bark on glycated hemoglobin level. 
In chronic treatment our results indicate that, daily administration of PRB; significantly improved the body weight in diabetic rats and the results were comparable with that of the standard drug glibenclamide. This increase in body weights of diabetic rats might be due to an enhancement in glycemic control and increased synthesis of structural proteins [31]. When PRB administered to glucose loaded normal rats fasted for $24 \mathrm{hrs}$, reduction in blood glucose was observed after $60 \mathrm{~min}$. The results of the study have shown a significant $(p<0.01)$ difference between the initial and final fasting plasma glucose levels of PRB and glibenclamide treated groups. There was a significant decrease in blood glucose level at different doses of PRB. The possible mechanism of hypoglycemic activity of PRB may be through increase in glucose metabolism [32]. The increased levels of triglycerides and total cholesterol are the principal factors responsible for the development of coronary heart disease and atherosclerosis, which are secondary complication of diabetes [33]. PRB showed significant decrease in triglycerides, total cholesterol, while an increase in HDL cholesterol has been observed in PRB treated diabetic rats, which indicate that HDL is inversely related to the total body cholesterol [34]. The effect of PRB to decrease triglycerides may be through increase of insulin levels. Insulin activates the enzyme lipoprotein lipase and hydrolyses triglycerides and the deficiency in insulin, thereby causes hyper triglyceridemia [35]. The elevation of biomarker enzymes such as SGOT, SGPT, and ALP was observed in diabetic control rats and indicates the hepatocellular damage [36]. The present study also indicates that injection of alloxan induces hepatic damage that elevates intracellular enzymes, such as transaminases and alkaline phosphate. The diabetic complications such as increased gluconeogenesis and ketogenesis may be due to elevated transaminase activity [37]. The hepatic damage was restored and the elevated transaminases were significantly reduced by PRB. Treatment of diabetic rats with PRB reduced the activity of these enzymes as compared to the untreated diabetic group. Hence PRB may act as a hepatoprotective agent. On the other hand, in the present study the level of renal function markers such as serum creatinine and serum urea which was increased in diabetic rats indicating the dysfunction of the kidney [38], were significantly inhibited by the treatment with PRB. Based on these findings, PRB may enhance the ability of the kidney to get rid of these waste products from the blood, as indicating a protective effect on the kidney of diabetic rats. Animals treated with PRB indicated a significant reduction in the glycalated hemoglobin level, which could be due to an improvement in insulin secretion, whereas glycalated hemoglobin level increased significantly in the untreated diabetic control group, which confirms the antidiabetogenic action of the PRB [39]. It is worth noting that the findings indicate that the curative effects could presumably be attributed to the occurrence of phenolic compounds like quercetin, rutin and chlorgenic acid in PRB reported previously by HPLC analysis [8]. Phenolics are known to rejuvenate the damaged beta cells in the alloxan induced diabetic rats and acts as insulin secretagogues and are reported to be antidiabetic [40]. It is well known that oxygen free radicals are involved in the diabetogenic action of alloxan therefore, plants containing flavonoids, triterpenoids have been proven to be effective in diabetes due their antioxidant property [41].

\section{Conclusion}

Our results suggest that $\mathrm{PRB}$ at different doses may provide a new therapeutic possibility against diabetes and diabetes-related complications. The possible mechanism by which PRB controls the diabetic condition may be due to certain biological compounds which may either induce the pancreas to secrete insulin from the existing beta cells or reduce blood glucose by related biochemical mechanisms. These facts are more strengthened as quercetin was isolated from PRB inhibiting $a$-amylase in our recent in vitro studies [20]. This indicates that the anti-hyperglycemic activity of Pinus roxburghii Sarg. may be due to the presence of flavanoids in the bark extract which acts on free radicals and enhance the beta cell regeneration against alloxan induced free radicals. In conclusion, it can be stated, that the Pinus roxburghii Sarg. has beneficial effects, in reducing the elevated blood glucose level and lipid profile of alloxan-induced-diabetic rats, but has no effect on normal rats. Thus, justifying its use as an anti-diabetic plant ethnopharmacologically.

\section{References}

1. http://www.who.int/mediacentre/factsheets/fs312/en/

2. Anjana RM, Pradeepa R, Deepa M, Datta M, Sudha V, et al. (2011) Prevalence of diabetes and pre-diabetes (impaired fasting glucose and/or impaired glucose tolerance) in urban and rural India: phase I results of the Indian Council of Medical Research-INdia DIABetes (ICMR-INDIAB) study. Diabetologia 54: 3022-3027.

3. Watkins PJ (1997) International Text Book of Diabetes Mellitus. John Wiley and Sons Ltd, UK.

4. Tota K, Rayabarapu N, Moosa S, Talla V, Bhyravbhatla B, et al. (2013) InDiaMed: A Comprehensive Database of Indian Medicinal plants for Diabetes. Bioinformation 9: 378-380.

5. Howes MJR, Simmonds MSJ (2005) Traditional Medicines for Modern Times: Plants used in the treatment of Diabetes. Taylor Francis Group, USA.

6. Kaushik P, Kaushik D, Khokra SL (2013) Ethnobotany and phytopharmacology of Pinus roxburghii Sargent: A plant review. J Integr Med 11: 371-376.

7. Khan I, Singh V, Chaudhary AK (2012) Hepatoprotective activity of Pinus roxburghii Sarg. wood oil against carbon tetrachloride and ethanol induced hepatotoxicity. Bangladesh J Pharmacol 7: 94-99.

8. Kaushik D, Kumar A, Kaushik P, Rana AC (2012) Analgesic and AntiInflammatory Activity of Pinus roxburghii Sarg. Adv Pharmacol Sci.

9. Kaushik D, Kumar A, Kaushik P, Rana AC (2012) Anticonvulsant activity of alcoholic extract of bark of Pinus roxburghii Sarg. Zhong Xi Yi Jie He Xue Bao 10: $1056-1060$.

10. Kaushik D, Kaushik P, Ajay Kumar, Rana AC, Chetan S, et al. (2013) GC-MS Analysis and Antimicrobial Activity of Essential Oil of Pinus roxburghii Sarg. from Northern India. Journal of Essential Oil Bearing Plants 16: 563-567.

11. Parihar $P$, Parihar L, Bohra A (2006) Antibacterial activity of extracts of Pinus roxburghii Sarg. Bangladesh J Bot 35: 85-86.

12. Kaushik P, Khokra SL, Rana AC, Kaushik D (2015) Evaluation of anticancer activity of Pinus roxburghii Sarg. against IMR-32 human neuroblastoma cancer cell line. IJPCR 7: 105-108.

13. Marles RJ, Farnsworth NR (1995) Antidiabetic plants and their active constituents. Phytomedicine 2: 137-189.

14. Chatterjee A, Dhara KP, Rej RN, Ghosh PC (1977) Hexacosylferulate, a phenolic constituent of Pinus roxburghii. Phytochemistry 16: 397-398.

15. Maimoona A, Naeem I, Saddiqe Z, Taskeen A (2011) Analysis of total flavonoids and phenolics in different fractions of bark and needle extracts of Pinus roxburghii and Pinus wallichiana. J Med Plant Res 5: 2724-2728.

16. Rawat U, Srivastava B, Semwal S, Sati OP (2006) Xanthones from Pinus roxburghii. J Indian Chem Soc 83: 391-392.

17. Willför S, Ali M, Karonen M, Reunanen M, Arfan M, et al. (2009) Extractives in bark of different conifer species growing in Pakistan. Holzforschung 63: 551558.

18. Kaushik P, Khokra SL, Rana AC, Kaushik D (2014) Pharmacophore Modeling and Molecular Docking Studies on Pinus roxburghii as a Target for Diabetes Mellitus. Advances in Bioinformatics.

19. Muthenna P, Suryanarayana P, Gunda SK, Petrash JM, Reddy GB (2009) Inhibition of aldose reductase by dietary antioxidant curcumin: mechanism of inhibition, specificity and significance. FEBS Lett 583: 3637-3642. 
Citation: Kaushik P, Khokra SL and Kaushik D (2015) Evaluation of Antidiabetic Potential of Pinus roxburghii Bark Extract in Alloxan Induced Diabetic Rats. J Pharmacogn Nat Prod 1: 105. doi:10.4172/2472-0992.1000105

20. Kaushik P Singh G, Khokra SL, Kaushik D (2015) Bioassay Guided Fractionation and $\alpha$-Amylase Inhibitory Activity of Flavanoid Isolated from Pinus roxburghii Sarg. Nat Prod Chem Res 3: 179.

21. OECD (2001) Guideline on Acute Oral Toxicity (AOT) Environmental Health and Safety Monograph Series on Testing and Adjustment No. 425.

22. Kaushik P, Kaushik D, Khokra SL, Sharma A (2010) Antidiabetic Activity of the Plant Abutilon indicum in Streptozotocin-Induced Experimental Diabetes in Rats. International Journal of Pharmacognosy and Phytochemical Research 2: $45-49$.

23. Jain S, Bhatia G, Barik R, Kumar P, Jain A, et al. (2010) Antidiabetic activity of Paspalum scrobiculatum Linn. in alloxan induced diabetic rats. J Ethnopharmacol 127: 325-328.

24. Jain SR (1968) Hypoglycaemic principle in Musa sapientum L. and its isolation. Planta Med 16: 43-47.

25. Sharma B, Siddiqui MS, Ram G, Yadav RK, Kumari A, et al. (2014) Rejuvenating of Kidney Tissues on Alloxan Induced Diabetic Mice under the Effect of Momordica charantia. Advances in Pharmaceutics.

26. Szkudelski T (2001) The mechanism of alloxan and streptozotocin action in $B$ cells of the rat pancreas. Physiol Res 50: 537-546.

27. Nayak SS, Pattabiraman TN (1981) A new colorimetric method for the estimation of glycosylated hemoglobin. Clin Chim Acta 109: 267-274.

28. Fischer LJ (1985) Drugs and chemicals that produce diabetes. Trends in Pharmacological Sciences 6: 72-75.

29. Tang LQ, Wei W, Chen LM, Liu S (2006) Effects of berberine on diabetes induced by alloxan and a high-fat/high-cholesterol diet in rats. J Ethnopharmaco 108: 109-115.

30. Swanston-Flatt SK, Day C, Bailey CJ, Flatt PR (1990) Traditional plant treatments for diabetes. Studies in normal and streptozotocin diabetic mice. Diabetologia 33: 462-464
31. Eliza J, Daisy P, Ignacimuthu S, Duraipandiyan V (2009) Antidiabetic and antilipidemic effect of eremanthin from Costus speciosus (Koen.)Sm., in STZinduced diabetic rats. Chem Biol Interact 182: 67-72.

32. Kaur G, Kamboj P, Kalia AN (2011) Antidiabetic and antihypercholesterolemic effects of aerial parts of Sida cordifolia Linn. on Streptozotocin-induced diabetic rats. Indian J Nat Prod Res 2: 428-434.

33. Goldbourt U, Yaari S, Medalie JH (1997) Isolated low HDL cholesterol as a risk factor for coronary heart disease mortality. A 21-year follow-up of 8000 men. Arterioscler Thromb Vasc Biol 17: 107-113.

34. Parab RS, Mengi SA (2002) Hypolipidemic activity of Acorus calamus L. in rats Fitoterapia 73: 451-455.

35. Jaeschke H, Gores GJ, Cederbaum Al, Hinson JA, Pessayre D, et al. (2002) Mechanisms of hepatotoxicity. Toxicol Sci 65: 166-176.

36. Ohaeri OC (2001) Effect of garlic oil on the levels of various enzymes in the serum and tissue of streptozotocin diabetic rats. Biosci Rep 21: 19-24.

37. Ghosh S, Suryawanshi SA (2001) Effect of Vinca rosea extracts in treatment of alloxan diabetes in male albino rats. Indian J Exp Biol 39: 748-759.

38. Kakadiya J, Shah M, Shah NJ (2010) Effect of nobivolol on serum diabetic marker and lipid profile in normal and streptozotocin-nicotinamide induced diabetic rats. RJPBCS 1: 329-334.

39. Hall PM, Cook JG, Sheldon J, Rutherford SM, Gould BJ (1984) Glycosylated hemoglobins and glycosylated plasma proteins in the diagnosis of diabetes mellitus and impaired glucose tolerance. Diabetes Care 7: 147-150.

40. Vessal M, Hemmati M, Vasei M (2003) Antidiabetic effects of quercetin in streptozocin-induced diabetic rats. Comp Biochem Physiol C Toxicol Pharmacol 135c: 357-364.

41. Jafri MA, Aslam M, Javed K, Singh S (2000) Effect of Punica granatum Linn. (flowers) on blood glucose level in normal and alloxan-induced diabetic rats. $J$ Ethnopharmacol 70: 309-314 